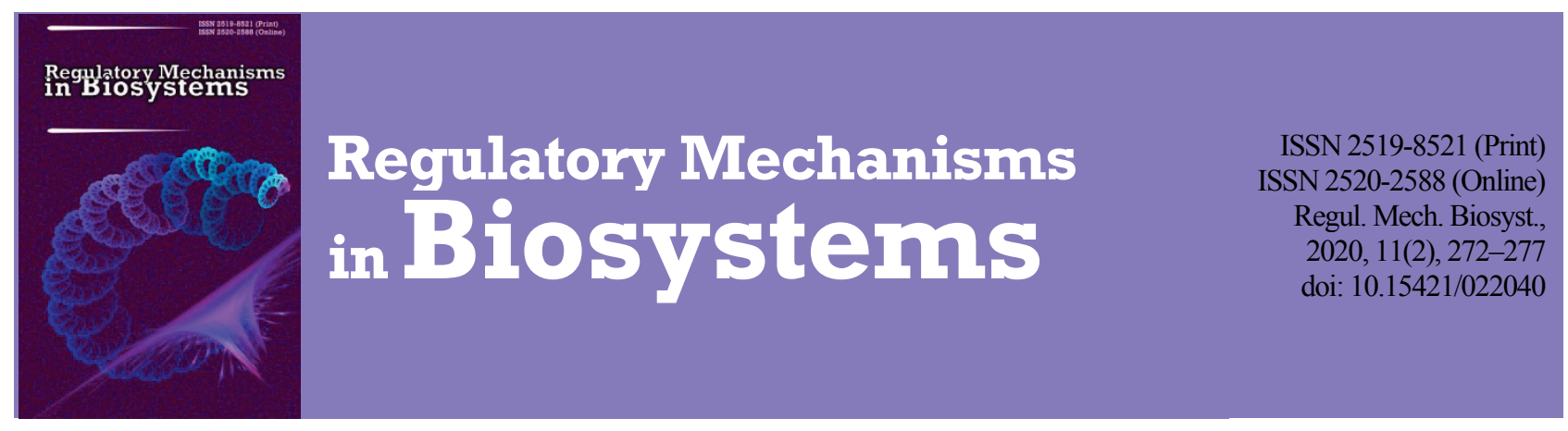

\title{
Low-molecular weight components of cow colostrum regulate bone marrow functions by modelling the redox-system of the organism
}

\author{
A. I. Bozhkov, S. L. Ohiienko, A. Y. Bondar, E. G. Ivanov, N. I. Kurguzova \\ V. N. Karazin Kharkov National University, Kharkov, Ukraine
}

Article info
Received 19.03.2020
Received in revised form
29.04 .2020
Accepted 30.04.2020
V.N. Karazin Kharkov
National University,
sq. Svobody, 4,
Kharkov, 61022,
Ukraine.
Tel.: +38-057-707-53-40.
E-mail: bozhkov@,
univer.kharkov.ua

\begin{abstract}
Bozhkov, A. I., Ohüenko, S. L., Bondar, A. Y., Ivanov, E. G., \& Kurguzova, N. I. (2020). Low-molecular weight components of cow colostrum regulate bone marrow functions by modelling the redox-system of the organism. Regulatory Mechanisms in Biosystems, 11(2), 272-277. doi:10.15421/022040
\end{abstract}

Colostrum is rich in various biologically active compounds such as immunotropic ones. Low molecular weight components were isolated from cow colostrum components (with a molecular weight of not more than $45 \mathrm{kDa}$ ). Their influence was investigated on intact Wistar Rattus norvegicus adult males in concentrations of $0.01,0.1,1.0$ and $5.0 \mathrm{~g} / 100 \mathrm{~g}$ of body weight. We determined content of lipid hydroperoxides and activity of serum glutathione peroxidase in blood serum, parameters of the bone marrow cells' (BMCs) behaviour in the in vitro system (proliferation ability, morphologically identifiable and unidentifiable type of cells, lifespan of eosinophils). Morphological identifiable cells were stab neutrophils, segmented neutrophils, metamyelocytes, myelocytes, lymphocytes, basophils, neutrophils, eosinophils, monocytes. The low doses of colostrum components $(0.01-0.10 \mathrm{~g} / 100 \mathrm{~g}$ of body weight) did not affect the ratio of morphologically identifiable/unidentifiable cells. Administration of colostrum components at low doses $(0.01 \mathrm{~g} / 100 \mathrm{~g}$ of weight) increased the ability of BMCs to proliferate in the in vitro system. A super-large dose of colostrum components ( $5 \mathrm{~g} / 100 \mathrm{~g}$ of body weight) was accompanied by a further loss of capacity for proliferation and cell death. Moreover, large doses of colostrum components resulted in change of balance to prooxidants (oxidants). The role of redox - system in BMCs functions was discussed. Large doses of colostrum components (1-5 g/100 g of body weight) were accompanied by a change of pro-antioxidant system balance. Only eosinophils were determined after administration of colostrum components in a large dose. It should be noted that the lifetime of eosinophils which developed under influence of colostrum components was greater than that of eosinophils obtained from control animals.

Keywords: morphotypes; oxidative stress; transfer factor; eosinophilia.

\section{Introduction}

Colostrum is a mixture of various substances with high biological activity that are formed in the mammary gland during the first few days after the beginning of lactation (Sanchez-Soto et al., 2017). This unique composition of growth factors and immunomodulating components induces "triggering" and ensures the formation not only of the immune system of newborns, but "program" the metabolism of the developing organism. The changes in colostrum composition can be noted within a few hours after the birth of calves. Newborns are already receiving milk from the mother after 5-6 days of lactation. Although the use of colostrum as a biologically active additive is widely used (Ascher et al., 2014; Meade et al., 2015; Stzepourginski et al., 2017) and especially its individual components - the transfer-factor, which is used to prevent and treat a number of pathologies (Bozhkov et al., 2016; Bozhkov et al., 2017), the features of the influence of the colostrum components on the adult and the old organism remains unclear. It was previously shown that colostrum components in large doses of $1-5 \mathrm{~g} / 100 \mathrm{~g}$ of body weight caused diarrhea and even death of some animals (10-15\%) (Bozhkov et al., 2017). However, the reception CC per os in small doses caused an antioxidant effect, activation of the immune system and restored a number of physiological parameters in animals with liver fibrosis, i.e. had a hepatoprotective effect (Kurguzova et al., 2015; Klein et al., 2017; Bozhkov et al., 2017; Bozhkov et al., 2018).

The investigation of the possible mechanisms of action of the colostrum components showed that they have a pronounced polyfunctional effect (Klein et al., 2017). We hypothesized that such polyfunctionality can be explained by the fact that colostrum components modulate the orga- nism's redox system, which is the basic level of regulation of the functions of biological systems (Asakawa \& Matsushita, 1980). At the present time, we assume that by changing the basic level of regulation colostrum components affect many of the organism's functional systems, i.e. there is a hierarchical system of regulation of metabolism. As is known, the formation of various pathologies including the violation of digestive functions (diarrhea induced with large doses of colostrum components) may be accompanied by cytotoxic effects at the level of BMCs.

Since the bone marrow produces immunocompetent cells, blood cells and the stem cell pool is localized in it, BMCs provide a cellular level of organism regulation (Javazon et al., 2004). On the background of changes in indices of the redox system and the function of digestive disorders, the direction of differentiation of bone marrow stem cells can change. In this regard, in the present study the number of cells in the bone marrow was determined in the work after administration of colostrum components of $0.01,0.1,1.0$ and $5.0 \mathrm{~g} / 100 \mathrm{~g}$ of body weight to mature rats $(3.0$ 3.5 months). The ratio of morphologically identifiable cells (lymphocytes, basophils, eosinophils, neutrophils, metamyelocytes, myelocytes, monocytes) to morphologically unidentifiable cells, the ability of BMCs to proliferation in the in vitro system and the time of preservation ("lifespan") of eosinophils in culture were determined.

\section{Materials and methods}

A total of 100 mature male Wistar rats were separated into experiments. These rats of 3 months old were obtained from the Research Institute of Biology, V. N. Karazin Kharkov National University (Kharkov, Ukraine). They were housed in a temperature-controlled room $\left(20-24^{\circ} \mathrm{C}\right)$ 
and adapted to a $12 \mathrm{~h}$ light $/ 12 \mathrm{~h}$ dark cycle. The animals were given free access to food and water before and during the study. All experimental procedures employed were approved by and conducted in accordance with bioethical rules (Council Directive 86/609/EEC, 1986) and with due consideration to circadian rhythms for the formation of biological responses. For 24 hours preceding isolation of bone marrow cells, the animals did not receive any food. Removing animals from the experiment was always carried out from 8 to $10 \mathrm{a}$. m. local time.

Colostrum components were obtained from colostrum only of the first milk yield after the parturition, as was described earlier (Bozhkov et al., 2017). For this purpose all lipid components were eliminated by three consequent separations. The proteins were eliminated by centrifugation at $6000 \mathrm{~g}$ during $10 \mathrm{~min}$ at room temperature and consequent membrane gel - filtration $(0.65,0.45,0.22)$. The protein content of colostrum components was assessed by electrophoresis in polyacrylamide gel. Colostrum components (Fig. 1) included proteins of molecular mass less than $45 \mathrm{kD}$ (Laemmli et al., 1970; Bozhkov et al., 2017). A suspension of free$\mathrm{ze}$ - dried colostrum components was dissolved in sterile distilled water before the administration and it was administrated per os.

The rats of the control group of animals (20) were administrated the sterile distilled water per os. The animals (Fig. 2) of the experimental group were divided into several groups that received colostrum components in different doses: $0.01 \mathrm{mg} / 100 \mathrm{~g}$ of body weight (20), $0.1 \mathrm{mg} / 100 \mathrm{~g}$ of body weight (20), $1 \mathrm{mg} / 100 \mathrm{~g}$ of body weight (20), $5 \mathrm{mg} / 100 \mathrm{~g}$ of body weight (20).

Before slaughtering, the animals were anesthetized with ether. When slaughtering animals, blood was collected and serum was prepared. Blood was collected into dry centrifuge tubes, incubated $30 \mathrm{~min}$ at $20^{\circ} \mathrm{C}$, and centrifuged for $15 \mathrm{~min}$ at $1500 \mathrm{~g}$. Determination of lipid hydroperoxides was carried out as described (Bagwe et al., 2015). The level of lipid hydro- peroxides was expressed in equivalents of MDA per $1 \mathrm{~mL}$ of serum. The activity rate of glutathione peroxidase (EC 1.11.1.9, GP) was measured in blood serum by spectrophotometry according to the method described in (Awan et al., 2018): we added $50 \mathrm{mM} \mathrm{K} / \mathrm{Na}$ phosphate buffer (pH 7.4) containing $1 \mathrm{mM}$ of EDTA, $0.15 \mathrm{mM}$ of NADPH, 1 unit of yeast glutathione reductase, $0.2 \%$ triton $\mathrm{X}-100$, and $3 \mathrm{mM}$ sodium aside for inhibiting catalase. The activity rate was expressed in nmol $\mathrm{NADPH} / \mathrm{min}$ per $1 \mathrm{~mL}$ of serum with allowance for the molar extinction coefficient $6.22 \times 10^{3} \mathrm{M}^{-1} \mathrm{~cm}^{-1}$.

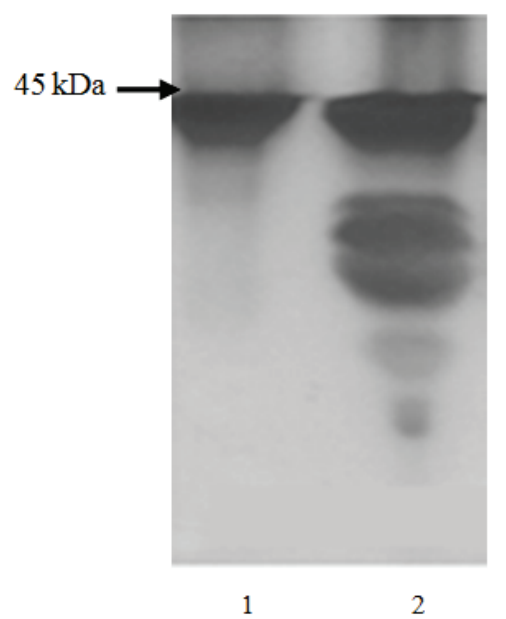

Fig. 1. Electrophoregram of the low molecular weight fraction of proteins: track 1 has a marker with a molecular weight of $45 \mathrm{kDa}$, track 2 is a sample with the low molecular components of colostrum

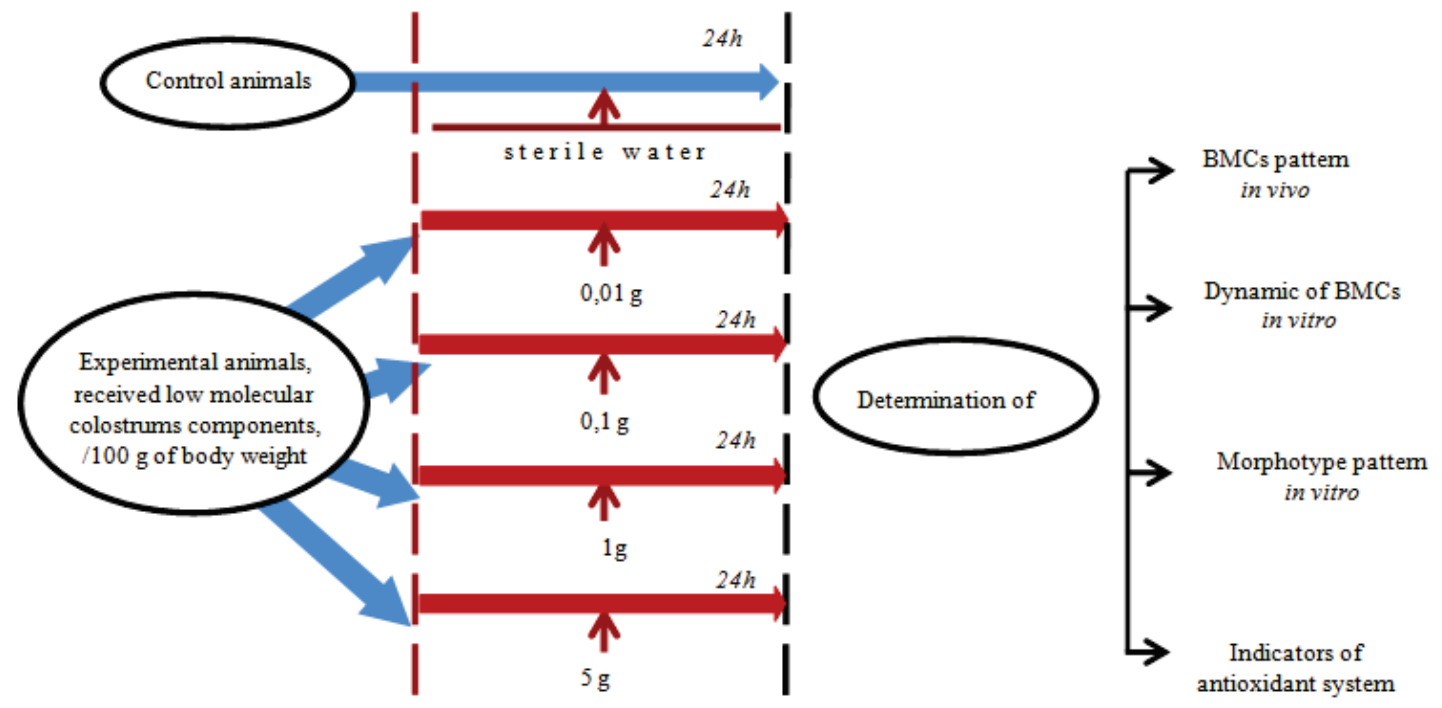

Fig. 2. Experimental scheme for establishing study animals: three independent experiments were performed

BMCs were obtained from both the femurs of animals in all the experimental groups, according to a method described previously (Paglia \& Valentine, 1967), and cultured in medium DMEM supplemented with antibiotics (8\% streptomycin and $8 \%$ gentamicin) and $20 \%$ inactivated fetal calf serum. The BMCs were cultivated for 4 days under standard conditions at $37{ }^{\circ} \mathrm{C}$ and in an atmosphere of $5 \% \mathrm{CO}_{2}$. The culture medium was not removed, and the initial concentration of the BMCs in the culture was maintained at 2 million cells $/ \mathrm{mL}$.

The number and viability of BMCs were determined, as described previously (Bozhkov et al., 2017). BMCs morphotypes were determined immediately after isolating the cells from the bone marrow and on days 2 and 4 of cultivation, as described previously (Bozhkov et al., 2017). The cells were stained with Romanowsky-Hymsa stain and were analysed at $100^{\times}$magnification using Primo Star iLED microscope (Zeiss, Germany) at magnification $100^{\times}$.

All data are presented as the means (x) and standard error (SE). Significant differences between groups were determined by a nonparametric
Mann-Whitney U test. All statistical analyses were performed using Statistica 8.0 (Statsoft Inc., USA) software pack. Differences between control and experimental groups were considered significant at $\mathrm{P}<0.05$.

\section{Results}

Administration of the colostrum components at small doses (0.01$0.05 \mathrm{~g} / 100 \mathrm{~g}$ of body weight) led to a decrease in the content of lipid hydroperoxides (LHP) in the blood serum by $24-45 \%$ in comparison with the intact control (Fig. 3a).

After the administration of colostrum components at the dose of $0.1 \mathrm{~g} / 100 \mathrm{~g}$ of body weight, this indicator did not differ from the control but when the dose was increased 10 times, it increased by $115 \%$. If the doses of colostrum components were increased 10 times, LHP increased by $115 \%$. A super-large dose of colostrum components $(5 \mathrm{~g} / 100 \mathrm{~g}$ of body weight) caused an increase in LHP content by two times in comparison with the intact control animals (Fig. 3a).Therefore, small doses (up to 
$0.05 \mathrm{~g} / 100 \mathrm{~g}$ of body weight) led to an antioxidant effect, and large doses (more than $1 \mathrm{~g} / 100 \mathrm{~g}$ of body weight) had a pro-oxidant effect. Therefore, we can expect the "parallel" decrease of activity of glutathione peroxidase (GP), which is one of the key antioxidant defense enzymes. It turned out that the activity of HP increased significantly in response to administration of colostrum components in small doses, and it was inhibited by $55-65 \%$ compared to control intact animals at high doses of colostrum components (Fig. 3a).
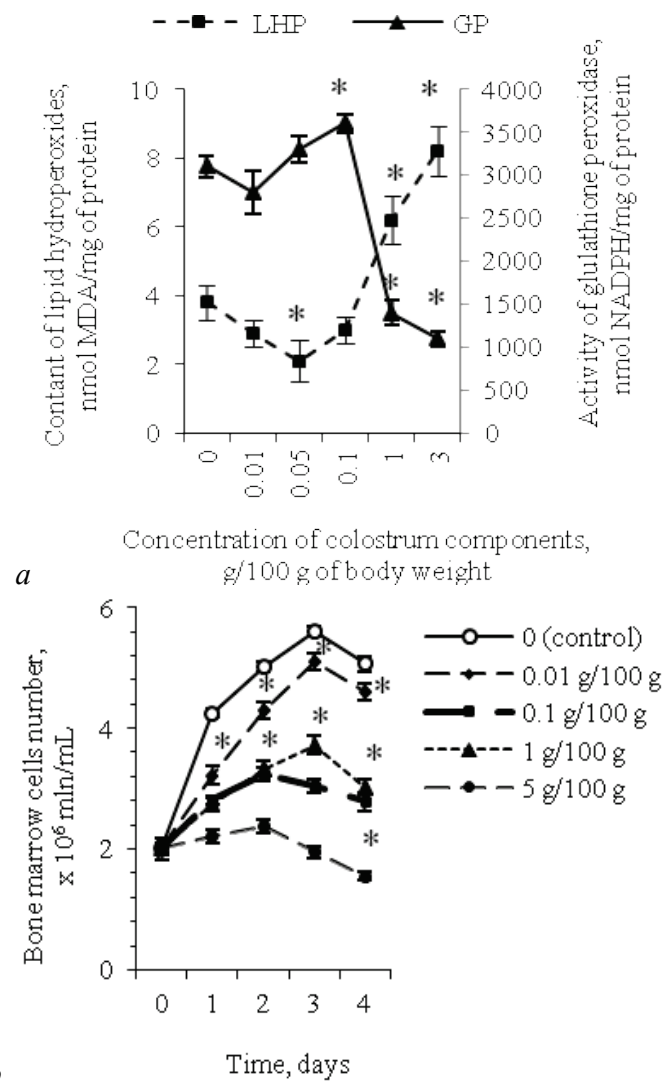

Fig. 3. Content of lipid hydroperoxides (LHP) and glutathione peroxidase (GP) activity $(a)$ in the serum obtained from control animals (0), and experimental animals after 24 hours of receiving the colostrum components at different doses, and the number of BMCs in primary culture from days 1 to 4 of cultivation in vitro (b): BMCs were obtained from control animals $(0)$, after administration per os of the colostrum components at different doses; error bars represent $\mathrm{x} \pm \mathrm{SE}$; the differences between samples were analyzed using the nonparametric Mann-Whitney U test $(\mathrm{P}<0.05$ compared with intact control)

Although these indicators do not reflect the activity of the entire proantioxidant system, they can serve as markers for the characteristics of the organism's redox system. Thus, using different doses of colostrum components, it is possible to shift the equilibrium both towards oxidants production and towards reducing agents increase in the adult organism.

Influence of different doses of the colostrum components on the BMCs number in primary culture in 1-4 days of cultivation in vitro. The culture medium was DMEM, and the initial concentration of BMC in the culture was maintained at 2 million cells $/ \mathrm{mL}$. BMCs obtained from intact animals (control) showed actively proliferation rate. After 3 days of cultivation, the number of BMCs increased by 2.8 times to comparison with the initial concentration (Fig. 3b). Administration of colostrum components at $0.01 \mathrm{~g} / 100 \mathrm{~g}$ of body weight had no effect on the BMC number. However, the BMC number was lower by $25,15,10$ and $10 \%$ in comparison with the intact control after 1,2, 3 and 4 days of cultivation (Fig. 3b). If the dose of the colostrum components was increased to $0.1 \mathrm{~g} / 100 \mathrm{~g}$ of body weight, then the number of BMC decreased after cultivation in vitro (Fig. 3b). At the same time, an increase of the colostrum components dose by 10 times $(1 \mathrm{~g} / 100 \mathrm{~g}$ of body weight $)$ did not affect the BMCs' number compared with a dose of $0.1 \mathrm{~g} / 100 \mathrm{~g}$ of body weight (Fig. 3b). In large doses, colostrum components showed a cytoto- xic effect on bone marrow cells. This effect was manifested in the in vitro system. Thus, administration of colostrum components to experimental animals per os influenced the proliferative activity of BMC after their transfer to the in vitro system. The pattern of BMCs' proliferative activity in the in vitro system is characterized by nonlinear dose dependence. BMC lost the ability to proliferate after the administration of super-large doses of colostrum components. This effect may be related to: 1 -rapid change of cellular populations' types in the bone marrow or 2 - with the change (epigenetic reprogramming) of BMC.

The influence of different doses of colostrum components on the pattern of bone marrow cellular morphotypes. To determine the morphological types of BMC, all cell types were divided into two groups: morphologically identifiable (stab and segmented neutrophils, myelocytes, metamyelocytes, lymphocytes, eosinophils, basophils, monocytes) that were identified microscopically and morphologically unidentifiable cells, which include mesenchymal stem cells and cells at different stages of differentiation. It should be noted that the number of BMC isolated from the two femurs in intact animals and animals which obtained the colostrum components was the same (Table 1).

Table 1

The number of BMCs in intact animals and after 24 hours of the administration of colostrum components at different doses $(x \pm S E)$

\begin{tabular}{lc}
\hline $\begin{array}{c}\text { Experimental groups, receiving colostrum } \\
\text { components } \mathrm{g} / 100 \mathrm{~g} \text { of body weight }\end{array}$ & Number of BMC, $\mathrm{x} 10^{6} \mathrm{cells} / \mathrm{mL}$ \\
\hline 0 (control) & $14.3 \pm 2.3$ \\
0.01 & $12.3 \pm 1.7$ \\
0.1 & $20.3 \pm 4.7$ \\
1.0 & $17.5 \pm 1.5$ \\
5.0 & $14.5 \pm 1.7$ \\
\hline
\end{tabular}

The total number of identified cells was about $60 \%$ in intact animals (Fig. 4). Administration of the colostrum components to experimental animals per os in doses of 1.0 and $5.0 \mathrm{~g} / 100 \mathrm{~g}$ of body weight did not influence the total number of morphologically identifiable cells in the bone marrow (Fig. 4). However, only $7-11 \%$ of the morphologically identified types of cells were in the culture after administration of the colostrum components in doses of 1.0 and $5.0 \mathrm{~g} / 100 \mathrm{~g}$ of body weight. As for unidentified cells, their number was $90 \%$ (Fig. 4).

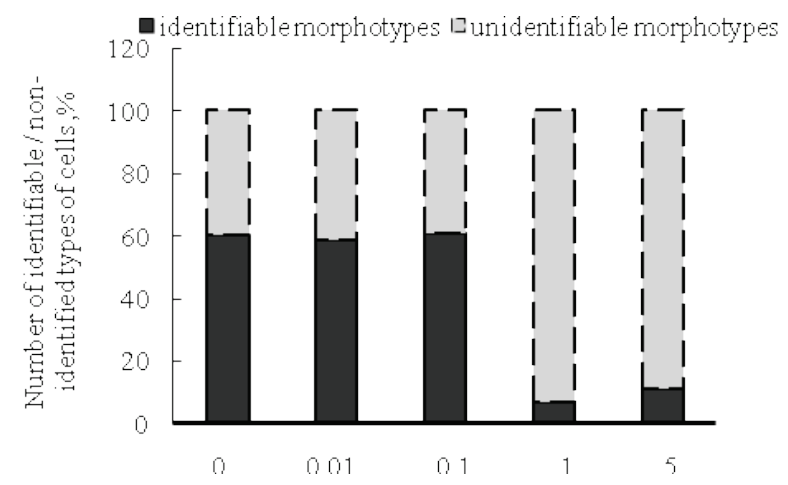

Concentration of colostrum components, $\mathrm{g} / 100 \mathrm{~g}$ of body weight

Fig. 4. Total number of morphologically identifiable morphotypes (stab neutrophils, segmented neutrophils, metamyelocytes, myelocytes, lymphocytes, basophils, neutrophils, eosinophils, monocytes) and non identifiable ones after administration of colostrums components per os

The pattern of morphologically identifiable types of BMCs was determined in the following series of experiments. It turned out that in the bone marrow of intact animals from morphologically identifiable types of cells, the most numerous were stab neutrophils (30\%), metamyelocytes (21\%), lymphocytes (13\%), eosinophils (about $8 \%$ ), and the least basophils (1.3\%) and myelocytes $(1.1 \%$, Table 2$)$.

Administration of the colostrum components to experimental animals per os in doses 0.01 and $0.1 \mathrm{~g} / 100 \mathrm{~g}$ of body weight did not affect the pattern of morphologically identified types of BMC (Table 2). At the same time, administration of the colostrum components in doses of 1.0 and $5.0 \mathrm{~g} / 100 \mathrm{~g}$ of body weight was accompanied by significant changes in 
the pattern of morphologically identifiable types of BMC. So, only eosinophils were identified among the morphologically identified types of cells. Unidentified cell types were represented by the remaining cells. Moreover, if the number of eosinophils in intact animals was $4.6 \%$, after administration of the colostrum components in a dose of $0.01 \mathrm{~g} / 100 \mathrm{~g}$ of body weight, their amount remained unchanged compared to the control variant (Fig. 5). Moreover, an increase in the dose from $1 \mathrm{~g} / 100 \mathrm{~g}$ of body weight to $5 \mathrm{~g} / 100 \mathrm{~g}$ of body weight was accompanied by an increase in the number of eosinophils from $6.7 \%$ to $11.0 \%$ of the total number of all bone marrow cells (Fig. 3, 4A, IV, V). Their amount was $6.7 \%$ after the administration of $0.1 \mathrm{~g} / 100 \mathrm{~g}$ of body weight, $6.4 \%$ after the administration of $0.1 \mathrm{~g} / 100 \mathrm{~g}$ of body weight and $11.0 \%$ after the administration of $5.0 \mathrm{~g} / 100 \mathrm{~g}$ of body weight. Consequently, administration of colostrum components in large doses led to eosinophilia in the bone marrow and a change in the pattern of cell morphotypes in the bone marrow. Moreover, increasing the dose from $1.0 \mathrm{~g} / 100 \mathrm{~g}$ of body weight to $5.0 \mathrm{~g} / 100 \mathrm{~g}$ body weight was accompanied by an increase in the number of eosinophils from $6.7 \%$ to $11.0 \%$ of the total number of all bone marrow cells (Fig. 5).

\section{Table 2}

Number (as a percentage of the total number of identified morphotypes) of stab neutrophils (NB), metamyelocytes (MT), lymphocytes (L), segmented neutrophils (NS), myelocytes (ML), basophils (B), eosinophils (E) and monocytes $(\mathrm{M})$ in bone marrow of the control group and after 24 hours of administration of the colostrum components per os at doses of 0.01 (II), 0.1 (III), 1.0 (IV) and 5.0 (V)/100 g of body weight

\begin{tabular}{lcccccccc}
\hline \multirow{2}{*}{$\begin{array}{c}\text { Experimental } \\
\text { groups }\end{array}$} & NB & MT & L & NS & ML & E & B & M \\
\cline { 2 - 9 }$y$ & 16.3 & 10.8 & 7.0 & 8.8 & 4.3 & 3.5 & 0.6 & 0.5 \\
control & 14.3 & 9.7 & 6.7 & 8.0 & 3.7 & 2.3 & 0.4 & 0.5 \\
0.01 & 13.3 & 7.8 & 7.7 & 8.0 & 3.3 & 6.3 & 0.4 & 0.3 \\
0.1 & 0 & 0 & 0 & 0 & 0 & 4.0 & 0 & 0 \\
1.0 & 0 & 0 & 0 & 0 & 0 & 7.3 & 0 & 0 \\
5.0 & & & & & & & & \\
\hline
\end{tabular}

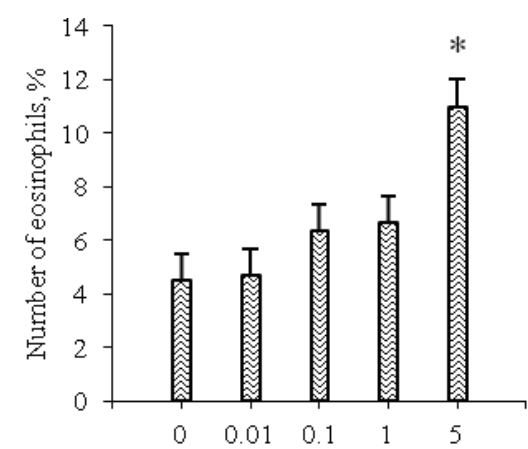

Doses of colostrum components, $\mathrm{g} / 100 \mathrm{~g}$ of body weight

Fig. 5. The number of eosinophils $(x \pm S E)$ in the case of their isolation in intact animals and after administration of colostrum components at a dose of $0.01,0.1,1.0$ and $5.0 \mathrm{~g} / 100 \mathrm{~g}$ of body weight: the differences between samples were analyzed using the nonparametric

Mann-Whitney $\mathrm{U}$ test $(\mathrm{P}<0.05$ compared with intact control $)$

As is known, eosinophils have a short "lifespan" in the bloodstream and after 6-12 hours are distributed into various tissues. It was of interest to determine the "lifetime" ("safety") in culture in vitro.

As can be seen from Figure 4, the pattern of morphologically identifiable types of bone marrow cells in the control group and obtained immediately after isolation from the bone marrow (variant A) and after 48 hours of incubation in an in vitro system (variant B), and after 96 hours of cultivation (variant $\mathrm{C}$ ) differed and this is expressed, to the greatest extent, for animal variants that received colostrum components in doses of $0.1,1.0$, and 5.0 (Fig. 4). To better illustrate the changes in the "lifespan" of eosinophils in the in vitro system, we presented them in Figure 6.

If eosinophils were isolated in intact animals, their number was $73 \%$ after 48 hours of cultivation. By 96 hours, their number was only 5\% (Fig. 6). Consequently, the death of eosinophils in the culture took place at different rates during the cultivation. If no more than $25-27 \%$ of the initial amount perished within 48 hours, then about $60-70 \%$ died in the next
48 hours if they were obtained from intact animals. If eosinophils were obtained from animals treated with the colostrum components at a dose of $0.01 \mathrm{~g} / 100 \mathrm{~g}$ of body weight, eosinophil death in culture was linear over time. After 48 hours, $50 \%$ of the eosinophils remained in culture and after 96 hours they were not detected (Fig. 6). At the same time, if the colostrum components were administrated in dose increasing to 10 times, the time of their preservation in the culture increased. Thus, cultivation for 48 hours did not affect their number, and in the next 48 hours about $70 \%$ of the culture died, and by the 96th hour of cultivation $26-30 \%$ of eosinophils were preserved, which is much larger than the control variant (Fig. 6). An increase in the dose of colostrum components up to 1.0 and $5.0 \mathrm{~g} / 100 \mathrm{~g}$ of body weight did not affect the amount of eosinophils in the culture by 48 hours. However, by 96 hours, $16-24 \%$ of the initial amount of eosinophils remained in the culture (Fig. 6).

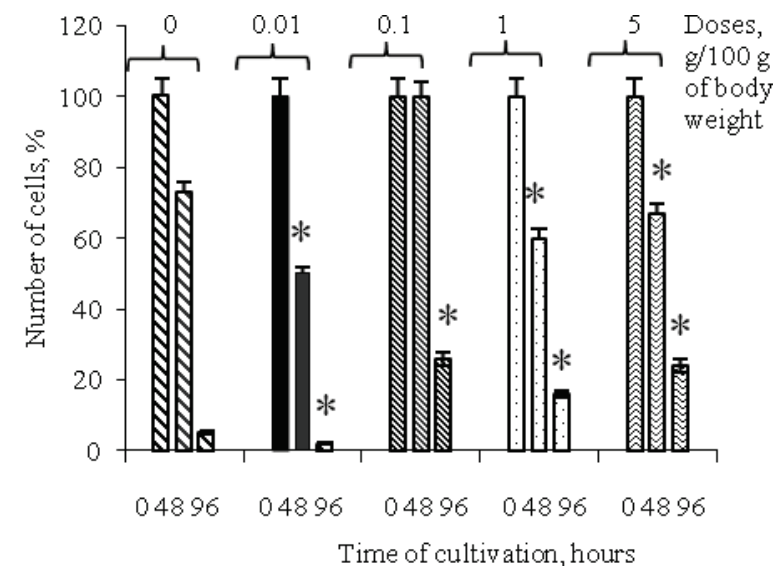

Fig. 6. The number of eosinophils $(\mathrm{x} \pm \mathrm{SE})$ as a percentage of the initial amount in culture in vitro and after 48 and 96 hours of cultivation under standard conditions in the case of their production in intact animals and after administration of colostrum components at a dose of $0.01,0.1,1.0$ and $5.0 \mathrm{~g} / 100 \mathrm{~g}$ of body weight: the differences between samples were analyzed using the nonparametric Mann-Whitney $U$ test $(\mathrm{P}<0.05$ compared with intact control)

Consequently, the colostrum components exerted different functional changes on the morphologically identifiable types of bone marrow cells, which had different effects on the pattern of morphologically identifiable bone marrow cells. The colostrum components also led to a change in the "lifespan" of eosinophils in the in vitro system. This dependence of these changes on concentration did not have a linear dose-dependent character. A smaller dose ( $0.01 \mathrm{~g} / 100 \mathrm{~g}$ of body weight) reduced eosinophils "lifespan" in culture, large doses increased it, compared with eosinophils obtained in the control group of animals. If eosinophils were formed in the bone marrow, they were different from eosinophils synthesized in intact animals for a greater "lifespan" in the in vitro system. These results suggest that the colostrum components not only promote eosinophilia, but also affect the metabolic and epigenetic characteristics of this type of BMC.

\section{Discussion}

The results of this study can be summarized to several general provisions, which need to be discussed.

1. The colostrum components have both antioxidant and prooxidant effects. This depends on the dose. The colostrum components have an antioxidant effect in doses of $0.05-0.10 \mathrm{~g} / 100 \mathrm{~g}$ of body weight, and in large doses (1-5 g/100 g of body weight), they have a prooxidant effect, so pronounced that it can be characterized as oxidative stress of the organism.

2. Administration of the colostrum components to animals per os influenced the qualitative and quantitative characteristics of bone marrow cells.

a. The total number of morphologically identifiable cells types (stab neutrophils, segmented neutrophils, metamyelocytes, myelocytes, lymphocytes, basophils, neutrophils, monocytes) did not change at doses of 0.01 and $0.1 \mathrm{~g} / 100 \mathrm{~g}$ of body weight, and decreased by $50 \%$ at doses of 1.0 and $5.0 \mathrm{~g} / 100 \mathrm{~g}$ of body weight. At the same time, the number of unidentified types of bone marrow cells increased and was about $90 \%$. 
b. The colostrum components exerted a dose-dependent effect on the pattern (ratio) of morphologically identifiable types of bone marrow cells. A dose of $0.01 \mathrm{~g} / 100 \mathrm{~g}$ of body weight did not affect the ratio of cell morphotypes, a dose of $0.1 \mathrm{~g} / 100 \mathrm{~g}$ of body weight slightly changed it, and at high doses of $1.0-5.0 \mathrm{~g} / 100 \mathrm{~g}$ of body weight in the bone marrow, only eosinophils, i.e. there was a bone marrow eosinophilia.

c. The colostrum components had an effect on the qualitative characteristics of bone marrow cells. This manifested itself in the dose-dependent inhibition of the proliferative activity of bone marrow cells in the in vitro system and influenced the length of their "lifespan" in the culture.

These results can be explained by the multistage nature of the dosedependent effect of the colostrum components. In the first stage (small doses up to $0.1 \mathrm{~g} / 100 \mathrm{~g}$ of body weight), the colostrum components exert a specific effect on bone marrow cells, after which they manifest a nonspecific effect (large doses of 1.0-5.0 g/100 $\mathrm{g}$ of body weight), which is manifested in the background of oxidative stress and inflammatory reaction. As is known, a large number of biologically active compoundscytokines, in particular, the transfer factor is the part of the colostrum components. It has a pronounced immunomodulatory effect and has an effect on immunogenesis in the bone marrow. Along with the transfer factor, colostrum is rich in other biologically active compounds. In particular, colostrum cytokines are able to regulate the functional activity of a large number of enzymes, including oxidative ones, to eliminate a number of pathologies. In our work, it was shown that the components of colostrum in small doses can eliminate oxidative stress and normalize a number of organism functions (Bozhkov et al., 2016).

Therefore, it can be argued that the administration of small doses of the colostrum components to adult animals exhibits a wide range of specific actions. This was manifested in small changes in the pattern of cell morphotypes in the primary cell culture and, to a greater extent, in the process of cell cultivating (Fig. 4), and in decreasing the rate of cell proliferation in culture (Fig. 3b). Thus, when small doses $(0.01-0.10 \mathrm{~g} / 100 \mathrm{~g}$ of weight) of the colostrum components were administered to animals, there was a slight change in the quantitative and qualitative characteristics of bone marrow cells that could affect the epigenetic and metabolic levels of regulation. Such changes can be considered as a response of bone marrow cells to a change in the microenvironment, in particular, the redox system of the organism.

Data were obtained that the administration of various doses of colostrum components to experimental animals had a dose-dependent effect on physiological parameters and, in particular, the functions of the gastrointestinal tract. Small doses of the colostrum components did not affect the functions of the gastrointestinal tract, whereas large doses led to intestinal dysfunction and diarrhea, and even death of some animals.

It should be noted that the abnormal function of the gastrointestinal tract correlated with the manifestation of oxidative stress in these animals. At this time, there was a global restructuring in the behaviour of bone marrow cells. In particular, only eosinophils and morphologically unidentifiable cell types were present from the morphologically identifiable cell types in the bone marrow. This can be explained, on the one hand, by the accelerated transport of mature cells into the bloodstream, and on the other hand, by a change in the physico-chemical characteristics of the microenvironment of bone marrow cells that are characteristic for the presence of the inflammatory process. Previously, it was shown that eosinophilia develops with diarnea, liver abscess, hepatitis and a number of other pathological conditions of the organism (Fujimori et al., 2017). Moreover, eosinophils which are formed against a background of gastrointestinal dysfunction and oxidative stress, differed in their functional characteristics from eosinophils which are formed under normal physiological conditions. In particular, they had a long "lifespan" in the in vitro system. These results suggest that morphologically similar cells can be different in their functional characteristics. We believe that this is because the occurring epigenetic and metabolic changes do not affect the morphological characteristics of the cells. These features require additional research.

Intensive research on the microbiota of the gastrointestinal tract showed that it is capable of self-regulation of functions due to the presence of its "own" nervous and endocrine systems. Regulation of the functions of the gastrointestinal tract has a complex hierarchical system of regulation, an important role in which is occupied by endogenous microorganisms.
The importance of the intestinal microflora is evidenced, on the one hand, by their quantitative composition. Comparatively to $10^{13}$ cells enter the human body, it is represented by $10^{14}-10^{16}$ cells. On the other hand, the endogenous microbiota provides important functions (detoxification function, metabolism participation proteins, the synthesis of vitamins, hormones and antibiotic substances, maintenance of water-salt metabolism and regulation of the activity of the immune system) (Rathe et al., 2014).

Consequently, the colostrum components that were administered per os to adult animals with a formed eubiosis (balance between the organism and the intestinal microflora) were accompanied, first, by changes in the functions of the gastrointestinal tract, and these were accompanied by systemic changes in the whole organism, including the redox system, which are manifested as an oxidative stress. It leads to changes in the functions of the bone marrow.

The state of the redox system can be considered as a basic (evolutionary-primary) mechanism of physico-chemical integration and regulation of all organism systems, including bone marrow.

According to available data, stem cells have a unique mechanism that ensures their protection against reactive oxygen species (ROS). According to the authors, this mechanism provides increased antioxidant protection and unique redox-dependent effects on the growth and differentiation of bone marrow cells. It can be assumed that oxidative stress, which was manifested with large doses of colostrum, inhibited the differentiation of bone marrow cells, which led to the accumulation of morphologically identifiable cell types in the bone marrow.

The stem cells of the bone marrow are located in a niche with a low ROS content. In such a niche, limiting the production of ROS is affected, which affects the intensity of the proliferation of bone marrow cells.

The results of this study show that an increase in ROS in the organism affects the qualitative and quantitative characteristics of bone marrow cells. This action can be attributed to nonspecific mechanisms of the influence of the colostrum components. Consequently, the dose-dependent effect of the colostrum components can be represented as a multi-stage process.

It is shown that hematopoietic and mesenchymal stem cells move between extra-embryonic and embryonic compartments. Such migration into different niches determines the direction of epigenetic modifications and the type of differentiation. However, as noted by a number of authors, the factors regulating homing and recruiting have not been fully established (Méndez-Ferrer et al., 2010). There are works that show that a number of growth factors are involved in these processes, in particular: stromal growth factor, hepatocyte growth factor, etc. (Saretzki et al., 2004). It can be assumed that among the components of colostrum there are factors regulating the recruitment of mesenchymal stem cells in the bone marrow, and with the nonspecific action of large doses of colostrum components and an increase in ROS products in the niche.

\section{Conclusion}

Colostrum components have both prooxidant, and antioxidant activity. This effect is dependent on doses. Modelling the functional system, colostrum components have an effect on the functional activity of the bone marrow cells.

\section{References}

Asakawa, T., \& Matsushita, S. (1980). Coloring condition of thiobarbituric acid test for detecting lipid hydroperoxides, Lipids, 15, 137-140.

Ascher, M. S., Gottlieb, A. A., \& Kirkpatrick, C. H. (Ed.). (2014). Transfer factor: Basic properties and clinical applications. Academic Press, London.

Awan, B., Turkov, D., Schumacher, C., Jacobo, A., McEnerney, A., Ramsey, A., \& Jao, L. E. (2018). FGF2 induces migration of human bone marrow stromal cells by increasing core fucosylations on $\mathrm{N}$-glycans of integrins. Stem Cell Reports, 11(2), 325-333.

Bagwe, S. L., Tharappel, L. J., Kaur, G., \& Buttar, H. S. (2015). Bovine colostrum: An emerging nutraceutical. Journal of Complementary and Integrative Medicine, 12, 175-185.

Bozhkov, A. I., Ivanov, E. G., Al Begai, M. A., Alsardia, M. M., \& Kurguzova, N. I. (2017). Low-molecular weight cow colostrum components in functional nutrition. Journal of Nutritional Therapeutics, 6(1), 11-17. 
Bozhkov, A. I., Ivanov, E. G., Kurguzova, N. I., Alsardia, M. M., Akzhigitov, R. A., Baranikova, S. Y., \& Chuprikova, A. S. (2018). The toxice of low molecular weight components of cow colostrums: The short-term and long-term effects. Journal of Nutritional Therapeutics, 6(4), 84-91.

Bozhkov, A. I., Ivanov, E. G., Kuznetsova, Y. A., Ohiienko, S. L., \& Bondar, A. Y. (2017). Copper-induced liver fibrosis affects the behavior of bone marrow cells in primary culture. Frontiers in Biology, 12, 271-279.

Bozhkov, A. I., Nikitchenko, Y. V., \& Al-Bahadly, A. M. M. (2016). Overeating in early postnatal ontogenesis forms metabolic memory and reduces lifespan. Journal of Gerontological and Geriatrics Research, 309(2), 3-12.

Bozhkov, A. I., Nikitchenko, Y. V., Lebid, K. M., Ivanov, E. G., Kurguzova, N. I., Gayevoy, S. S., \& Al Begai, M. A. Y. (2017). Low molecular weight components from various sources eliminate oxidative stress and restore physiological characteristic of animals at early stages of $\mathrm{Cu}$-induced liver fibrosis development. Translational Biomedicine, 8(2), 22-32.

Fujimori, M., França, E. L., Morais, T. C., Fiorin, V., de Abreu, L. C., \& HonórioFrança, A. C. (2017). Cytokine and adipokine are biofactors can act in blood and colostrum of obese mothers. Biofactors, 43(2), 243-250.

Javazon, E. H., Beggs, K. J., \& Flake, A. W. (2004). Mesenchymal stem cells: Paradoxes of passaging. Experimental Hematology, 32(5), 414- 425.

Klein, B. Y., Tamir, H., Ludwig, R. J., Glickstein, S. B., \& Welch, M. G. (2017) Colostrum oxytocin modulates cellular stress response, inflammation, and autophagy markers in newborn rat gut villi. Biochemical and Biophysical Research Communications, 487(1), 47-53.

Kurguzova, N. I., Bozhkov, A. I., Nikitchenko, Y. V., Al Begai, M. A. Y., Goltvyansky, A. V., Alsardia, M. M. A., \& Bozhkov, A. A. (2015). Interconnection of antitoxic and antioxidant systems of the organism under the action of natural low molecular complex - fungidol. American Journal of Biomedical and Life Sciences, 2, 25-32.

Laemmli, U. K., Laemmli, D. K., Laemmli, U., Laemli, U. K., Lammeli, U., Lammeli, U. K., \& Laemmli, V. K. (1970). Denaturing (SDS) discontinuous gel electrophoresis, 227, 680-685.

Meade, J. C., Levine, A. H., Melanson, D. A., \& Cvinar, J. F. (2015). U.S. Patent No. 9,084,669. Washington, DC: U.S. Patent and Trademark Office.

Méndez-Ferrer, S., Michurina, T. V., Ferraro, F., Mazloom, A. R., MacArthur, B. D., Lira, S. A., \& Frenette, P. S. (2010). Mesenchymal and haematopoietic stem cells form a unique bone marrow niche. Nature, 466(7308), 829-834.

Paglia, D. E., \& Valentine, W. N. (1967). Studies on the quantitative and qualitative characterization of erythrocyte glutathione peroxidase. The Journal of Laboratory and Clinical Medicine, 70(1), 158-169.

Rathe, M., Müller, K., Sangild, P. T., \& Husby, S. (2014). Clinical applications of bovine colostrum therapy: A systematic review. Nutrition Rewires, 72, 237-254.

Sanchez-Soto, E., Ponce-Ramos, R., Hernandez-Gutierrez, R., Gutierrez-Ortega, A., Alvarez, A. H., Martinez-Velazquez, M., \& Herrera-Rodriguez, S. E. (2017). Colostrum proinflammatory cytokines as biomarkers of bovine immune response to bovine tuberculosis (bTB). Microbial Pathogenesis, 103, 57-64

Saretzki, G., Armstrong, L., Leake, A., Lako, M., \& Zglinicki, T. (2004). Stress defense in murine embryonic stem cells is superior to that of various differentiated murine cell. Stem Cells, 22(6), 962-971.

Stzepourginski, I., Nigro, G., Jacob, J. M., Dulauroy, S., Sansonetti, P. J., Eberl, G., \& Peduto, L. (2017). CD34+ mesenchymal cells are a major component of the intestinal stem cells niche at homeostasis and after injury. Proceedings of the National Academy of Sciences, 114(4), E506-E513. 